DOI: 10.1002/adma.201101086

\title{
Protection and Promotion of UV Radiation-Induced Liposome Leakage via DNA- Directed Assembly with Gold Nanoparticles
}
This is the peer reviewed version of the following article: Dave, N. and Liu, J. (2011), Protection and Promotion of UV Radiation-Induced Liposome Leakage
By Neeshma Dave, and Juewen Liu* via DNA-Directed Assembly with Gold Nanoparticles. Adv. Mater., 23: 3182- 3186. doi:10.1002/adma.201101086, which has been published in final form at http://dx.doi.org/10.1002/adma.201101086. This article may be used for non- commercial purposes in accordance with Wiley Terms and Conditions for Self-
[*] Prof. J. Liu, Mrs. N. Dave Archiving.

Department of Chemistry, Waterloo Institute for Nanotechnology, University of Waterloo, 200 University Avenue West, Waterloo, Ontario, N2L 3G1, Canada

E-mail: liujw@uwaterloo.ca

Keywords: liposomes, gold nanoparticles, DNA, assembly, radiation

A hallmark of nanoscience is the control of materials property as a function of nanoparticle size and inter-particle distance. ${ }^{[1]}$ One classical example is DNA-directed assembly of inorganic nanoparticles. ${ }^{[2]}$ Via DNA surface functionalization, nanoparticles with different compositions, sizes, or shapes can be brought in close proximity using a linker DNA resulting in programmable and reversible changes in their physical properties and in turn offering multi-functionality to such systems. Recently, DNA-functionalized inorganic nanoparticles have also been tested for drug delivery. ${ }^{[3]}$ Since most inorganic nanoparticles with interesting optical and magnetic properties are non-porous, drugs have to be attached to the surface resulting in a limited loading capacity. ${ }^{[4]}$

On the other hand, soft materials such as liposomes have been shown to be a safer alternative with high drug loading capacity. In recent years, the amount of work involving DNA-functionalized liposomes is rapidly increasing. ${ }^{[5]}$ Liposomes alone, however, do not possess the unique optical or magnetic properties of inorganic nanoparticles. If liposomes and inorganic nanoparticles can be assembled in a programmable manner, multifunctional nanostructures combining advantages of both particles can be obtained. ${ }^{[6]}$ We herein report the reversible assembly of DNA-functionalized liposomes and gold nanoparticles (AuNPs). Contrary to the majority of previous reports where AuNPs promoted radiation induced 


\section{Submitted to

liposome leakage, we found that using linker DNA created a short but finite separation between AuNPs and liposomes, and this separation hindered heat transfer. By tuning this separation, it is possible to either promote liposome leakage or inhibit it.

As shown in Figure 1, our hybrid nanostructure contained two kinds of nanoparticles. The "soft" particle was a liposome (DOPC:cholesterol:DOPG:MPB-PE, wt/wt = 10:8:1:1). DNA conjugation was achieved by reacting the MPB-PE component of the liposome containing a maleimidophenyl functionality with thiol-modified DNA (DNA1). The liposome hydrodynamic size was determined to be $103 \mathrm{~nm}$ using dynamic light scattering. We estimated the number of DNA on each liposome to be 365 with a coupling efficiency of $\sim 21 \%$ (see Supporting Information). Liposomes can also be used to encapsulate drugs or fluorophores for biomedical and analytical applications. The "hard" particle was a $\sim 13 \mathrm{~nm}$ AuNP functionalized with a different thiol-modified DNA (DNA2). We chose to use AuNPs since they can effectively absorb radiation energy and the assembly of AuNPs can be monitored via a visible color change. Although several Au-liposome hybrids have been reported, ${ }^{[7,8]}$ most of these materials were prepared by non-specific and irreversible electrostatic interactions. ${ }^{[8]}$ In our system, programmable and reversible DNA hybridization interaction allows a precise control on the property of the assembly.

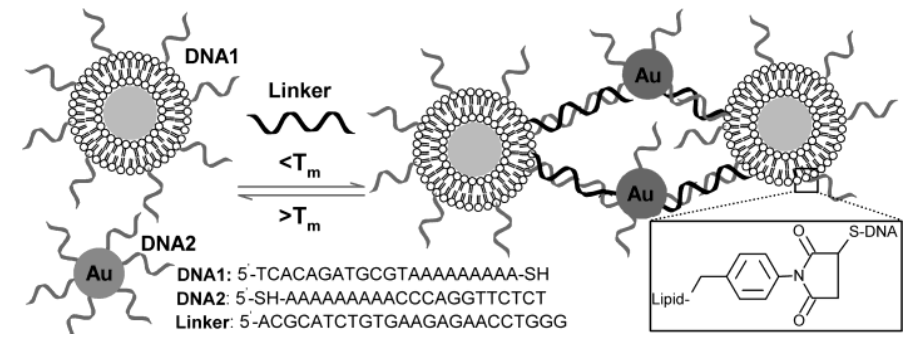

Figure 1. Schematics of DNA-directed reversible assembly of DNA-functionalized liposomes and AuNPs. The DNA sequences and DNA-liposome linkage are also shown.

The dispersed AuNPs have a characteristic extinction peak at $520 \mathrm{~nm}$ (Figure 2a) with a red color. Upon addition of the DNA-functionalized liposomes and linker DNA, a gradual 


\section{Submitted to

color change to purple was observed and the $520 \mathrm{~nm}$ peak shifted slightly to longer wavelength and decreased in intensity, suggesting the formation of assembled AuNPs with liposomes. In the case of $\mathrm{Au}-\mathrm{Au}$ assembly, where the above-mentioned liposome was replaced by AuNPs with the same DNA sequence, a significant decrease in intensity of the shifted $520 \mathrm{~nm}$ peak was observed because of better surface plasmon coupling. To determine the optimal ratio of AuNPs and liposomes, $4 \mathrm{nM}$ of the AuNPs was mixed with varying concentrations of liposome. The resulting products were characterized using UV-vis spectroscopy. To quantitatively measure this assembly process, the extinction ratio of $650 \mathrm{~nm}$ over $520 \mathrm{~nm}$ was used (Figure 2b). With increasing concentration of liposome, the ratio initially increased, indicating formation of assemblies. After reaching a maximum with $\sim 0.2$ nM liposome (AuNP:liposome $=20: 1$ ), the ratio started to decrease due to dilution of AuNP density of the liposome surface at high liposome concentrations. As a control experiment, if the linker DNA was omitted, no color change was observed (see Supporting Information). Therefore, aggregation was specific and only achieved in the presence of linker DNA. 

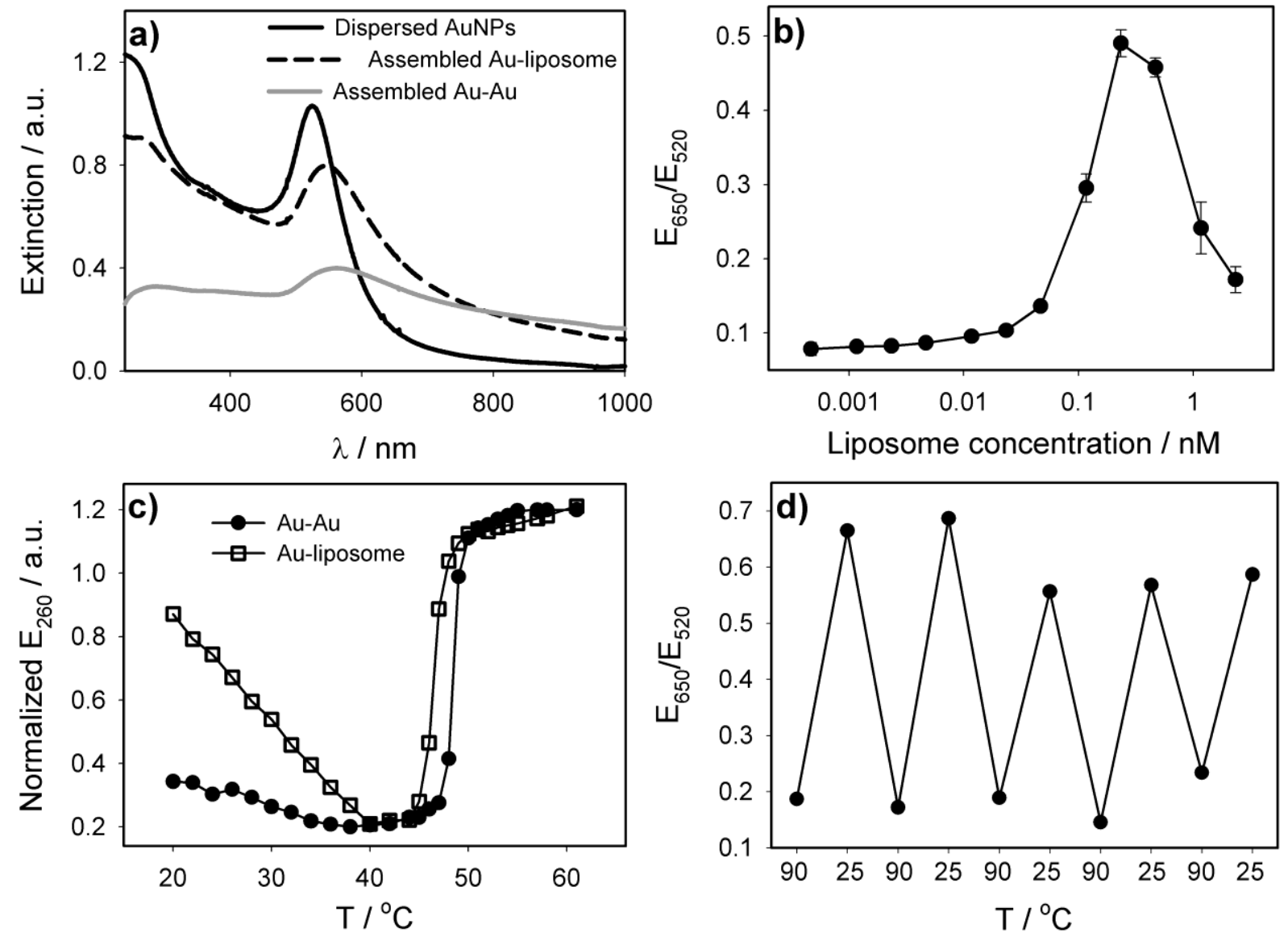

Figure 2. (a) UV-vis spectra of dispersed and assembled AuNPs and liposomes. (b) Assembly of AuNPs as a function of liposome concentration. 4 nM AuNPs were used for all the samples. (c) Melting curves of $\mathrm{Au}-\mathrm{Au}$ and Au-liposome aggregates linked by the same DNAs. (d) Reversible assembly and melting of AuNP-liposome controlled by temperature.

An important characteristic of DNA-linked nanostructures is their sharp melting transition. ${ }^{[9,10]}$ To study the melting of our hybrid nanostructures, the extinction at $260 \mathrm{~nm}$ was monitored as a function of temperature. As shown in Figure 2c, a sharp melting transition with $\mathrm{T}_{\mathrm{m}}=47{ }^{\circ} \mathrm{C}$ was obtained. A similar $\mathrm{T}_{\mathrm{m}}$ value was observed (within $2{ }^{\circ} \mathrm{C}$ ) for the $\mathrm{Au}-\mathrm{Au}$ assembly linked by the same linker DNA. We further tested reversibility of the assembly process by cycling the temperature between 90 and $25^{\circ} \mathrm{C}$, where the extinction ratio changed reversibly (Figure 2d). The reversibility of our aggregates indicated that the functionalized liposomes and AuNPs were stable and aggregation was indeed achieved via DNA 


\section{Submitted to

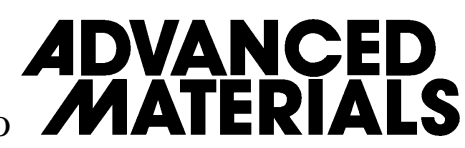

hybridization. This also distinguished our system from previously reported AuNP-liposome hybrids, where aggregation was achieved through simple electrostatic interactions. ${ }^{[8]}$

To characterize the structure of our AuNP-liposome assemblies, cryo-TEM was used. Two vitrified samples were prepared with two different sizes of liposome (Figure 3a and b for $103 \mathrm{~nm}$ liposome and Figure 3c for $258 \mathrm{~nm}$ liposome). The assembled structures were formed for each liposome size, suggesting good generality and programmability of DNA-directed assembly irrespective of the liposome size. All the aggregates were very large (e.g. more than several micrometers), suggesting that the AuNPs and liposomes were extensively crosslinked. AuNPs were not evenly distributed but followed the surface contour of the liposome and clustered between them (Figure 3c). In some regions, the liposomes were completely encapsulated by AuNPs (Figure 3b). In general, the AuNPs were more sparsely distributed in Au-liposome compared to typical $\mathrm{Au}-\mathrm{Au}$ assemblies, which may explain the smaller shift in the UV-vis spectrum for the Au-liposome assemblies as shown in Figure 2a.

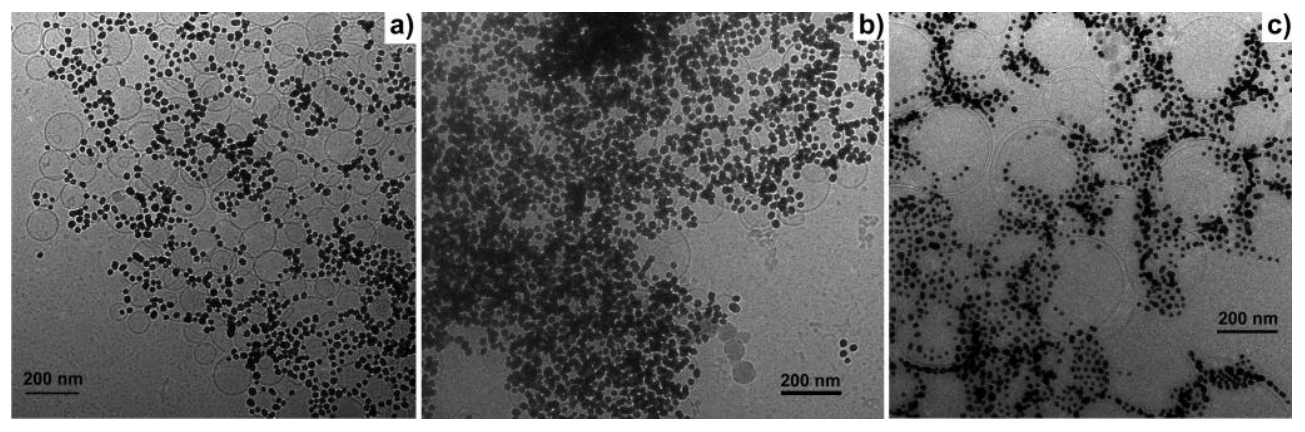

Figure 3. Cryo-TEM micrographs of AuNP-liposome assemblies. The average liposome size is $103 \mathrm{~nm}$ in (a) and (b), and $258 \mathrm{~nm}$ in (c). (a) and (b) are collected on the same TEM grid.

To test liposome stability and integrity during DNA-directed assembly process, calcein was encapsulated in the liposome at a self-quenching concentration (100 mM) prior to the addition of AuNPs and linker DNA. Liposome leakage can therefore be monitored by an increase in calcein fluorescence. Our results suggest that assembly with AuNPs did not increase calcein leakage from the liposome (see Supporting Information). 


\section{Submitted to

Since AuNPs can effectively absorb radiation energy, the DNA linkage provided us a unique opportunity to study distance-dependent heat transfer at nanometer scale, which can lead to applications such as light-triggered drug release ${ }^{[7,8]}$ For the initial proof of concept, a 302 nm UV light was used. For this study, we chose to use calcein-loaded DPPC liposomes, because DPPC has a phase transition temperature of $41^{\circ} \mathrm{C}$, where a significant leakage rate is expected. While at room temperature, little leakage occurs. ${ }^{[8]}$

We tested three DPPC assembly states. In addition to free DPPC liposomes (Figure 4a), the liposomes were also assembled with AuNPs in the same way as shown in Figure 1 where there was a $\sim 8 \mathrm{~nm}$ separation defined by the 24-mer linker DNA (Figure 4b). By changing the DNA sequence on the AuNPs to be complementary to the DNA1 on the liposome, the AuNPs were positioned in close proximity to the liposome (Figure 4c). 
Submitted to
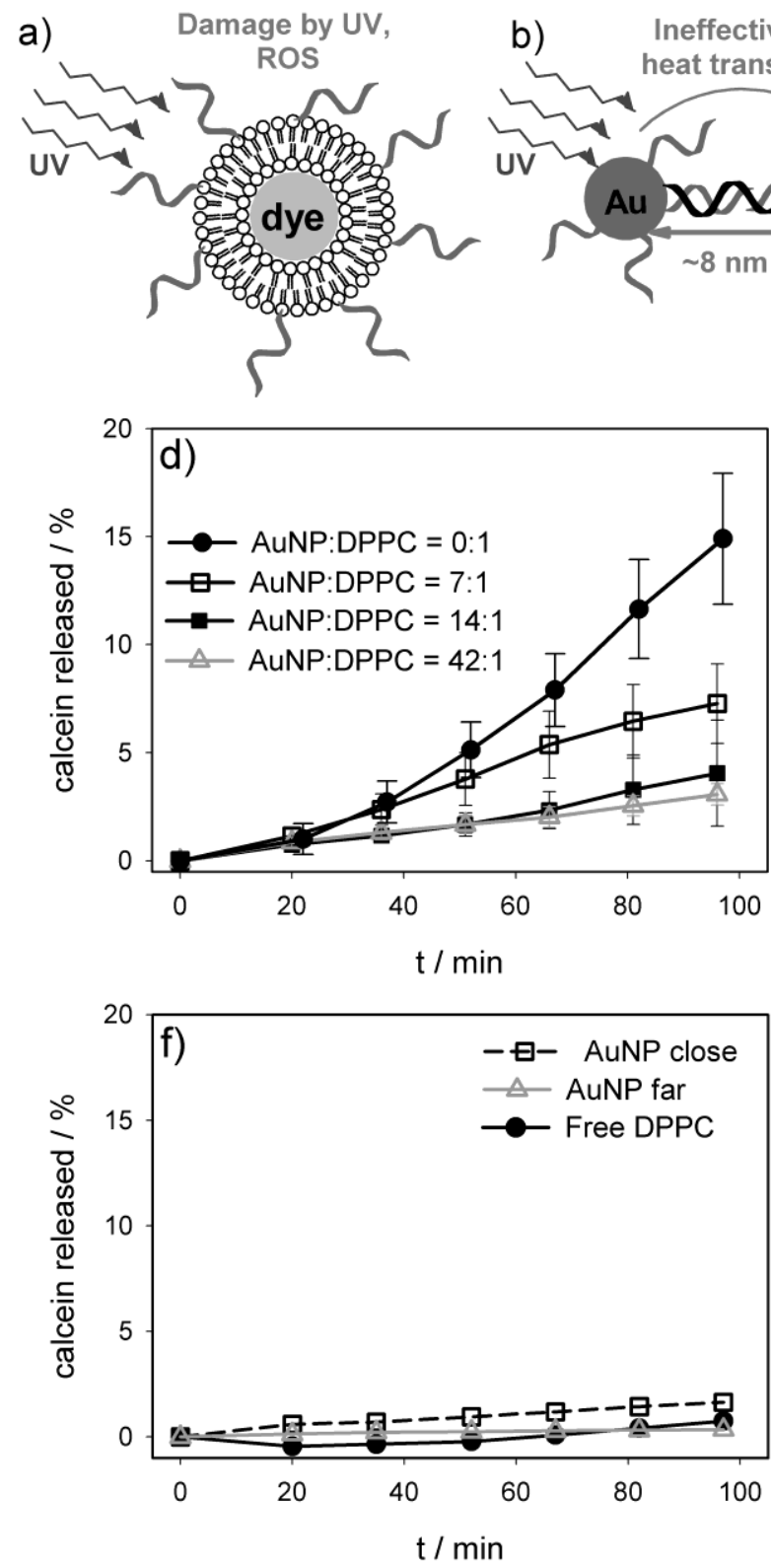

c) Effective

b) Ineffective
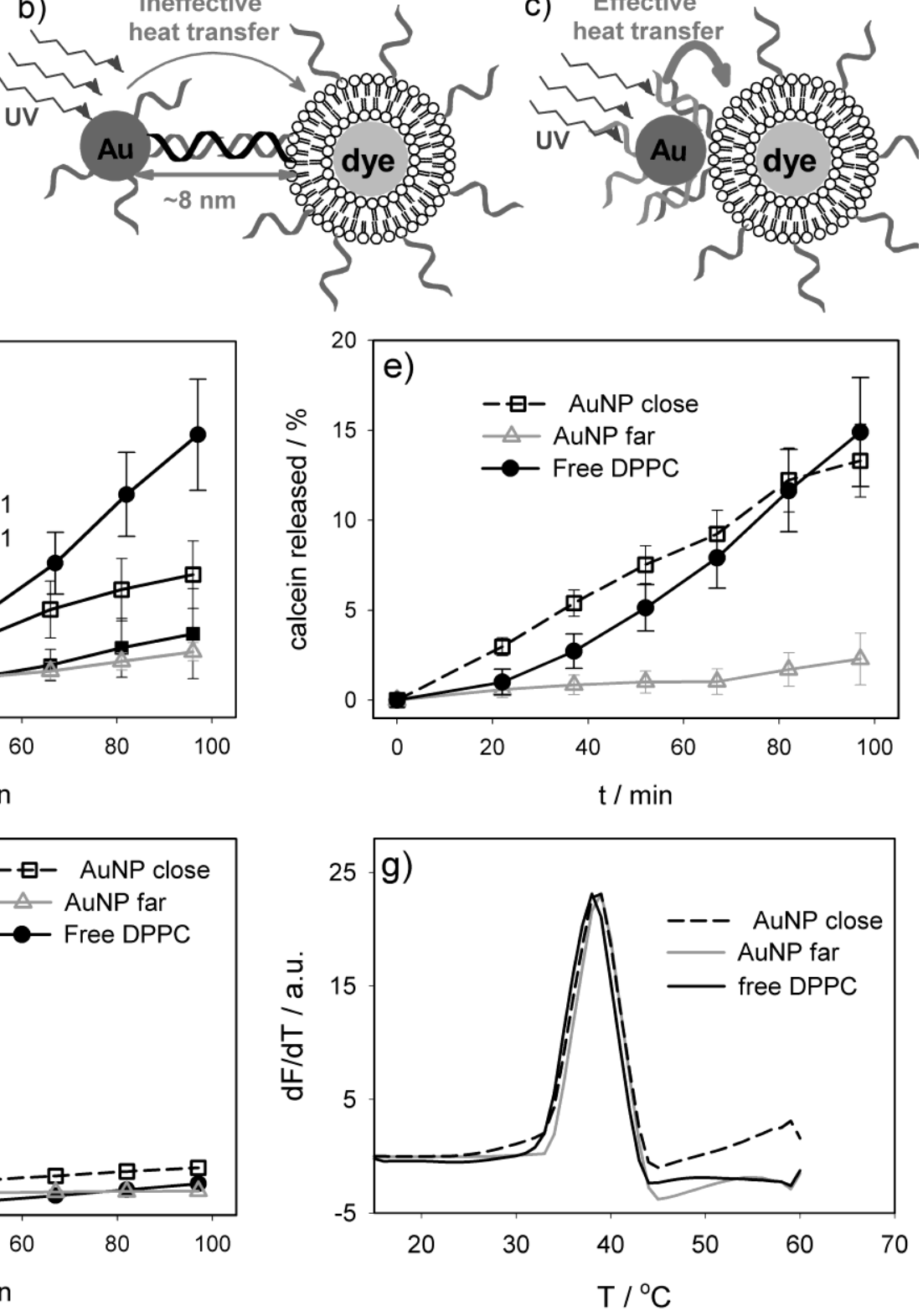

Figure 4. Schematics of UV induced calcein loaded DPPC leakage of free liposomes (a), and when AuNP and liposome were far (b) or close (c) to each other. Percentage of calcein release as a function of AuNP to liposome ratio (d) or AuNP-to-liposome distance (e) under UV irradiation, or in dark (f). (g) Release of calcein as a function of temperature in the absence of UV irradiation. The y-axis is the amount of fluorescence increase at each temperature.

The liposome samples were loaded in a 96-well PCR plate and exposed to $302 \mathrm{~nm}$ UV light. At designated time points, the plate was read by a real time PCR thermocycler and the final fluorescence was also read after breaking the liposomes using Triton X-100. As shown 


\section{Submitted to

in Figure 4d (black dots), free DPPC liposomes showed a time-dependent leakage. With an accumulative irradiation for about $100 \mathrm{~min}, \sim 15 \%$ calcein release was observed. We attribute this leakage to UV-induced liposome damage. For example, UV light is known to generate reactive oxygen species (ROS) that can make pores on DPPC liposome. ${ }^{[10]}$ In the presence of ascorbate to remove ROS, the amount of leakage was reduced (see Supporting Information), supporting that ROS was playing a role in the process. If the liposomes were assembled with AuNPs as shown in Figure 4b, leakage was almost completely inhibited (Figure 4d, gray triangles). In majority of the previous work, it has been shown that adsorbed AuNPs promoted radiation induced liposome leakage; this is the first time that a protection effect was observed. The protection effect is related to the amount of AuNP used. Reducing the AuNP to liposome ratio resulted in increased leakage as shown in Figure 4d.

We found that in most previous work, AuNPs were either embedded within the hydrophobic bilayer or directly adsorbed on the bilayer surface through electrostatic interactions, giving a close-to-zero distance between AuNPs and liposomes. In our DNAlinked system, there was a $\sim 8 \mathrm{~nm}$ separation between AuNPs and liposomes defined by the rigid DNA. Therefore, we attribute this protection effect to the absorption of UV light by AuNPs and thus damage to liposome was reduced minimizing liposome leakage. The absorbed UV was converted to heat. Due to the $8 \mathrm{~nm}$ distance, the heat cannot be effectively transferred to the liposome surface, making heat induced leakage also ineffective. Therefore, AuNPs reduced both radiation and heat induced leakage in this system.

To test this hypothesis, several control experiments were performed. First, we prepared AuNP-DPPC aggregates shown in Figure 4c, where the AuNPs and liposomes were positioned very closely to allow for more effective heat transfer. For this type of aggregates, we indeed observed a relatively fast calcein release compared (Figure 4e, open squares). Second, if the samples were incubated at room temperature in dark, no significant leakage was observed. This was true for all of the samples (Figure 4f), suggesting UV radiation was 


\section{Submitted to

responsible for increased calcein leakage. Finally, to ensure that AuNP attachment did not perturb the liposome releasing profile or phase transition behavior, we exposed the three types of liposomes at varying temperatures and the amount of calcein release at each temperature was recorded. As shown in Figure 4g, all the liposomes showed the same temperaturedependent releasing profile; the fastest releasing was observed at $\sim 40{ }^{\circ} \mathrm{C}$, the phase transition temperature of DPPC.

In summary, we have prepared and characterized a new DNA-linked hybrid nanostructure containing both soft and hard nanoparticles. Such a system is useful for fundamental understanding on the interaction between light, AuNPs, and liposomes at nanoscale, since the length of linker DNA can be easily varied. For example, in contrary to previous reports where AuNPs always promoted radiation induced liposome leakage, we observed both promotion and protection effects, depending on the distance between the AuNPs and liposomes defined by DNA. At the same time, this system can potentially be used for triggered drug release applications. For drug delivery, the size of the aggregates must be significantly reduced and this can be potentially achieved using a higher AuNP to liposome ratio. Although UV light was used for a proof-of-concept in this work, near IR light can also heat up AuNPs with a better tissue penetration property.

\section{Experimental}

Preparation of liposomes: Liposomes were prepared by the standard extrusion method. DOPC, cholesterol, DOPG, and MPB-PE were mixed in chloroform at a weight ratio of 10:8:1:1 with a total lipid mass of $2.5 \mathrm{mg}$. In another lipid formulation, DPPC and MPB-PE were mixed at a 19:1 ratio. Chloroform was removed under a gentle $\mathrm{N}_{2}$ flow in the fume hood and trace amount of residual chloroform was removed by storing the samples in a vacuum oven overnight. The lipid was stored at $-20{ }^{\circ} \mathrm{C}$ prior to use. To prepare liposome, the lipid was hydrated with $0.5 \mathrm{~mL}$ of buffer $\mathrm{A}(150 \mathrm{mM} \mathrm{NaCl}, 25 \mathrm{mM}$ HEPES, pH 7.6) at room 


\section{Submitted to

temperature with occasional sonication. Therefore, the lipid concentration was $5 \mathrm{mg} / \mathrm{mL}$. To prepare DPPC liposomes, all the operations were carried out at temperatures above $50{ }^{\circ} \mathrm{C}$. To prepare calcein loaded liposomes, $100 \mathrm{mM}$ disodium calcein in $100 \mathrm{mM}$ HEPES pH 7.6 were used to hydrate the lipids. The hydrated lipids were extruded through a polycarbonate membrane 21 times. The membrane pore diameters include 50, 100 and $400 \mathrm{~nm}$. The prepared liposomes were used immediately for DNA conjugation. Free calcein was removed by passing the samples through a Pd-10 gel filtration column or by centrifugation and removal of the supernatant.

DNA conjugation to liposomes: Thiol modified DNAs were activated by TCEP (TCEP:DNA=2:1 molar ratio) in $\mathrm{pH} 5.0,40 \mathrm{~mm}$ acetate buffer for $1 \mathrm{hr}$ at room temperature. In a typical reaction, $50 \mu \mathrm{L}$ of the above prepared liposomes were reacted with a final of 50 $\mu \mathrm{M}$ activated DNA overnight. After DNA conjugation, the liposomes formed aggregates due to DNA mediated self-aggregation and were centrifugation at $4{ }^{\circ} \mathrm{C}$ to remove free DNA.

Preparation of AuNP-liposome aggregates: Literature procedures were followed to prepare AuNPs and to attach thiol-modified DNAs to AuNPs. ${ }^{[2 c]}$ In a typical reaction, 4 nM AuNPs were reacted with $0.2 \mathrm{nM} 103 \mathrm{~nm}$ liposomes in the presence of $200 \mathrm{nM}$ of the linker DNA in buffer B (300 mM NaCl with $25 \mathrm{mM}$ HEPES, pH 7.6). To prepare $258 \mathrm{~nm}$ liposome-AuNP assemblies, the same mass concentration of liposomes were used. The mixture was incubated at $50{ }^{\circ} \mathrm{C}$ for $5 \mathrm{~min}$ and then allowed to cool slowly to room temperature to form aggregates.

DPPC leakage experiment: DNA-functionalized calcein containing DPPC liposomes (extruded through $100 \mathrm{~nm}$ membrane) were prepared. To form aggregates with AuNPs, 300 $\mu \mathrm{L}$ of DNA2- or DNA3-functionalized AuNPs ( 10 nM) were concentrated down to $40 \mu \mathrm{L}$ in buffer B. To 30, 10, or $5 \mu \mathrm{L}$ of this AuNP solution, $1.5 \mu \mathrm{L}$ of $5 \mathrm{mg} / \mathrm{mL}$ DPPC-DNA1 and a final of $10 \mu \mathrm{M}$ of linker DNA were added. This mixture was left at $4{ }^{\circ} \mathrm{C}$ overnight to allow aggregation. The formed aggregates were centrifuged at $4{ }^{\circ} \mathrm{C}$ at $8000 \mathrm{rpm}$ for $8 \mathrm{~min}$. The 


\section{Submitted to

supernatant was discarded and the aggregates were washed twice with $100 \mu \mathrm{L}$ buffer $\mathrm{B}$. Finally the aggregates were dispersed in $40 \mu \mathrm{L}$ buffer B. These aggregates and free DPPC (loaded with $100 \mathrm{mM}$ calcein and purified by Pd-10 column) were always kept on ice prior to use. For the UV radiation experiment, $10 \mu \mathrm{L}$ of the aggregates or free DPPC was added to $100 \mu \mathrm{L}$ of buffer B. $5 \mu \mathrm{L}$ of this solution was then added to each well of a 96-well PCR plate. The fluorescence was determined using a real time PCR thermocycler (Bio-Rad, CFX96) in the FAM channel (fluorescence $=I_{0}$ ) at $25^{\circ} \mathrm{C}$. The $302 \mathrm{~nm}$ UV lamp of a gel documentation system (Alpha Innotech, FluorChem FC2) was used. After each 15-20 min exposure, the plate was read using the PCR machine (fluorescence intensity $=I_{T}$ ). Finally, $1 \mu \mathrm{L}$ of $5 \%$ Triton X100 was added to each well and the plate was read (fluorescence intensity $=I_{F}$ ). The fraction of leakage was calculated to be $\left(I_{T}-I_{0}\right) /\left(I_{F}-I_{0}\right)$.

\section{Acknowledgements}

Funding for this work is from the University of Waterloo and NSERC of Canada. ((Supporting Information is available online from Wiley InterScience or from the author)).

Received: 24 March 2011 Revised: 19 April 2011 Published online: 31 May 2011

References:

a) E. Katz, I. Willner, Angew. Chem., Int. Ed. 2004, 43, 6042; b) N. L. Rosi, C. A. Mirkin, Chem. Rev. 2005, 105, 1547; c) U. Feldkamp, C. M. Niemeyer, Angew. Chem., Int. Ed. 2006, 45, 1856; d) F. A. Aldaye, A. L. Palmer, H. F. Sleiman, Science 2008, 321, 1795; e) W. Zhao, M. A. Brook, Y. Li, Chembiochem 2008, 9, 2363; f) C. Lin, Y. Liu, H. Yan, Biochemistry 2009, 48, 1663; g) J. Liu, Z. Cao, Y. Lu, Chem. Rev. 2009, 109, 1948. 


\section{Submitted to

[2] a) C. A. Mirkin, R. L. Letsinger, R. C. Mucic, J. J. Storhoff, Nature 1996, 382, 607; b) A. P. Alivisatos, K. P. Johnsson, X. Peng, T. E. Wilson, C. J. Loweth, M. P. Bruchez, Jr, P. G. Schultz, Nature 1996, 382, 609; c) J. J. Storhoff, R. Elghanian, R. C. Mucic, C. A. Mirkin, R. L. Letsinger, J. Am. Chem. Soc. 1998, 120, 1959.

[3] N. L. Rosi, D. A. Giljohann, C. S. Thaxton, A. K. R. Lytton-Jean, M. S. Han, C. A. Mirkin, Science 2006, 312, 1027.

[4] S. Dhar, W. L. Daniel, D. A. Giljohann, C. A. Mirkin, S. J. Lippard, J. Am. Chem. Soc. 2009, 131,14652 .

[5] a) C. Yoshina-Ishii, S. G. Boxer, J. Am. Chem. Soc. 2003, 125, 3696; b) C. YoshinaIshii, G. P. Miller, M. L. Kraft, E. T. Kool, S. G. Boxer, J. Am. Chem. Soc. 2005, 127, 1356; c) Y. H. M. Chan, B. van Lengerich, S. G. Boxer, Proc. Natl. Acad. Sci. U.S.A. 2009, 106, 979; d) P. A. Beales, T. K. Vanderlick, J. Phys. Chem. A 2007, 111, 12372; e) G. Stengel, R. Zahn, F. Hook, J. Am. Chem. Soc. 2007, 129, 9584; f) G. Stengel, L. Simonsson, R. A. Campbell, F. Hook, J Phys Chem B 2008, 112, 8264; g) U. Jakobsen, A. C. Simonsen, S. J. Vogel, J. Am. Chem. Soc. 2008, 130, 10462; h) M. Hadorn, P. Eggenberger Hotz, PLoS ONE 2010, 5, e9886; i) M. Loew, L. Kang, L. Dahne, R. Hendus-Altenburger, O. Kaczmarek, J. Liebscher, D. Huster, K. Ludwig, C. Bottcher, A. Herrmann, A. Arbuzova, Small 2009, 5, 320; j) H. J. Liang, D. Harries, G. C. L. Wong, Proc. Natl. Acad. Sci. U.S.A. 2005, 102, 11173; k) F. Patolsky, A. Lichtenstein, I. Willner, J. Am. Chem. Soc. 1999, 122, 418; 1) M. P. Thompson, M. P. Chien, T. H. Ku, A. M. Rush, N. C. Gianneschi, Nano Lett. 2010, 10, 2690; m) F. B. Bombelli, F. Betti, F. Gambinossi, G. Caminati, T. Brown, P. Baglioni, D. Berti, Soft Matter 2009, 5, 1639; n) N. Dave, J. Liu, ACS Nano, 2011, 5, 1304.

[6] a) M. R. Rasch, E. Rossinyol, J. L. Hueso, B. W. Goodfellow, J. Arbiol, B. A. Korgel, Nano Lett. 2010, 10, 3733; b) A. Corma, U. Diaz, M. Arrrica, E. Fernandez, I. Ortega, Angew. Chem. Int. Ed. 2009, 48, 6247. 


\section{Submitted to

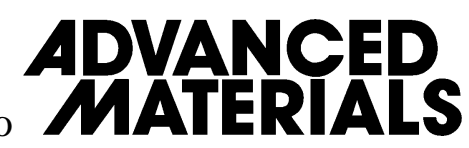

[7] a) G. H. Wu, A. Milkhailovsky, H. A. Khant, C. Fu, W. Chiu, J. A. Zasadzinski, J. Am. Chem. Soc. 2008, 130, 8175; b) D. Aili, M. Mager, D. Roche, M. M. Stevens, Nano Lett. 2010, 11, 1401.

[8] a) C. Kojima, Y. Hirano, E. Yuba, A. Harada, K. Kono, Colloid. Surface. B. 2008, 66, 246; b) T. K. Sau, A. S. Urban, S. K. Dondapati, M. Fedoruk, M. R. Horton, A. L. Rogach, F. D. Stefani, J. O. Radler, J. Feldmann, Colloid. Surface. A. 2009, 342, 92; c) Y. D. Jin, X. H. Gao, J. Am. Chem. Soc. 2009, 131, 17774 d) L. Paasonen, T. Laaksonen, C. Johans, M. Yliperttula, K. Kontturi, A. J. Urth, Control. Release 2007, 122, 86; e) T. S. Troutman, S. J. Leung, M. Romanowski, Adv. Mater. 2009, 21, 2334; f) A. Yaghmur, L. Paasonen, M. Yliperttula, A. Urtti, M. Rappolt, J. Phys. Chem. Lett. 2010, 1, 962; g) L. Paasonen, T. Sipila, A. Subrizi, P. Laurinmaki, S. J. Butcher, M. Rappolt, A. Yaghmur, A. Urtti, M. Yliperttula, J Control Release 2010, 147, 136; h) X. An, F. Zhang, Y. Zhu, W. Shen, Chem. Comm. 2010, 46, 7202; i) D. V. Volodkin, A. G. Skirtach, H. Mohwald, Angew. Chem. Int. Ed. 2009, 48, 1807; j) J. S. Katz, J. A. Burdick, Macromolecular Bioscience 2010, 10, 339; k) L. J. E. Anderson, E. Hansen, E. Y. Lukianova-Hleb, J. H. Hafner, D. O. Lapotko, J. Control. Release 2010, 144, 151; 1) W.-K. Fong, T. L. Hanley, B. Thierry, N. Kirby, B. J. Boyd, Langmuir 2010, 26, 6136; m) A. S. Urban, M. Fedoruk, M. R. Horton, J. O. Radler, F. D. Stefani, J. Feldmann, Nano Lett. 2009, 9, 2903; n) T. S. Troutman, J. K. Barton, M. Romanowski, Adv. Mater. 2008, 20, 2604.

[9] R. Elghanian, J. J. Storhoff, R. C. Mucic, R. L. Letsinger, C. A. Mirkin, Science 1997, 277, 1078-1080.

[10] a) H. L. Smith, M. C. Howland, A. W. Szmodis, Q. Li, L. L. Daemen, A. N. Parikh, J. Majewski, J. Am. Chem. Soc. 2009, 131, 3631; b) C. K. Yee, M. L. Amweg, A. N. Parikh, J. Am. Chem. Soc. 2004, 126, 13962-13972. 